\title{
Nonischemic Mitral Regurgitation: Prognostic Value of Nonsustained Ventricular Tachycardia after Mitral Valve Surgery
}

\author{
Oladipupo Olafiranye ${ }^{a} \quad$ Clare A. Hochreiter ${ }^{b}$ Jeffrey S. Borer ${ }^{a}$ \\ Phyllis G. Supino ${ }^{a}$ Edmund M. Herrold ${ }^{a}$ Adam S. Budzikowski ${ }^{a}$ \\ Ofek Y. Hai ${ }^{\mathrm{a}}$ Dany Bouraad ${ }^{\mathrm{a}}$ Paul D. Kligfield ${ }^{\mathrm{c}}$ Leonard N. Girardi ${ }^{\mathrm{b}}$ \\ Karl H. Krieger ${ }^{\text {b }}$ O. Wayne Isom ${ }^{\text {b }}$ \\ aDivision of Cardiovascular Medicine, Department of Medicine, The Howard Gilman Institute for Heart Valve \\ Disease, State University of New York Downstate Medical Center, Brooklyn, N.Y., ${ }^{b}$ Department of Cardiothoracic \\ Surgery, and 'Division of Cardiology, Weill Medical College of Cornell University, New York, N.Y., USA
}

\section{Key Words}

Ejection fraction · Mitral regurgitation · Mitral valve surgery $\cdot$ Ventricular tachycardia

\section{Abstract}

Background: Nonsustained ventricular tachycardia (VT), frequent in unoperated severe mitral regurgitation (MR), confers mortality risk [sudden death (SD) and cardiac death (CD)]. The prognostic value of VT after mitral valve surgery (MVS) is unknown; we aimed to define this prognostic value and to assess its modulation by left (LV) and/or right (RV) ventricular ejection fraction (EF) for mortality after MVS. Methods: In 57 patients (53\% females, aged $58 \pm 12$ years) with severe MR prospectively followed before and after MVS, we performed 24-hour ambulatory electrocardiograms approximately annually. LVEF and RVEF were determined within 1 year after MVS by radionuclide cineangiography. Results: During $9.52 \pm 3.49$ endpoint-free follow-up years, late postoperative CD occurred in 11 patients (7 SD, 4 heart failures). In univariable analysis, $>1$ VT episode after MVS predicted SD $(p<0.01)$ and CD (SD or heart failure; $p<$ 0.04). Subnormal postoperative RVEF predicted CD ( $p<$
0.04). When adjusted for preoperative age, gender, etiology or antiarrhythmics, both postoperative VT and RVEF predicted $C D(p \leq 0.05)$. When postoperative VT and RVEF were both in the multivariable model, only subnormal RVEF predicted CD $(p<0.04)$. Among those with normal RVEF, VT $>1$ episode predicted SD $(p=0.03)$. Conclusion: Postoperative VT and subnormal RVEF predict late postoperative deaths in nonischemic MR. Their assessment may aid patient management.

Copyright $\odot 2013$ S. Karger AG, Basel

\section{Introduction}

Mitral valve surgery (MVS) for mitral regurgitation (MR) ameliorates congestive symptoms [1,2] and, based on comparisons of operated and unoperated observational cohorts, appears to improve survival compared with no surgery. This apparent survival benefit seems to occur irrespective of symptom status $[3,4]$ and of preoperative left ventricular (LV) and/or right ventricular (RV) ejection fraction (EF) [5]. However, cardiac death (CD), frequently occurring suddenly (sudden death, SD), limits

\section{KARGER}

E-Mail karger@karger.com

www.karger.com/crd
(C) 2013 S. Karger AG, Basel

0008-6312/13/1242-0108\$38.00/0 
otherwise expected survival late after $\operatorname{MVS}[3,4,6]$. Though relatively uncommon, SD also occurs in unoperated severe MR [5, 7, 8], increasingly as LVEF deteriorates [9]. Rarely, SD occurs even among those with isolated, pure MR and normal LVEF, suggesting an underlying myocardial predisposition [9]. The effect of surgery on this predisposition is not known. Predictors of postoperative survival $[10,11]$ have been sought by several investigators. Preoperative LVEF and RVEF are powerful independent predictors of long-term survival after MVS [3, 7 , $10,12]$. However, available data, limited largely to early postoperative events, have failed to reveal a relation between pre- or postoperative ventricular arrhythmia and postoperative outcome [13]. Nonsustained ventricular tachycardia (VT) is frequent among patients with unoperated MR [8] and may persist after MVS. Nonetheless, the relation of VT to late postoperative survival and the interaction between VT, LVEF and RVEF on survival have not been evaluated. Therefore, we undertook to determine this relation in a cohort that has undergone MVS for MR.

\section{Methods}

\section{Patient Selection}

All patients were enrolled in our prospective study of the natural progression of regurgitant valvular disease and its predictors, as previously described $[7,14]$. For inclusion in the current analysis, patients must have undergone MVS for hemodynamically severe, nonischemic, pure, isolated chronic MR (verified by catheterization), 24-hour ambulatory electrocardiography (AECG) within 18 months after MVS, and follow-up after postoperative AECG. Thus, patients were excluded if they had clinically evident coronary artery disease or more than mild additional valve or other structural heart disease. Referral for MVS was determined by the patient's primary cardiologist and was unrelated to the study protocol. Initially by protocol, and subsequently as part of routine clinical evaluation, all patients in our natural history study undergo annual AECG, 2-dimensional and Doppler echocardiography, as well as rest and exercise radionuclide cineangiography (RNCA), the tests relevant for this analysis. However, patients or their primary physicians have occasionally chosen not to perform such testing in any single year.

Between February 1981 and June 2001, 96 patients in our natural history study underwent MVS. Of this group, 57 patients met the inclusion criteria. Study entry for this analysis was truncated at 2001 to allow for 10-year follow-up in all patients with this chronic disease.

\section{Procedures}

Ambulatory Electrocardiography

Two-channel, continuous 24-hour AECG was recorded from $\mathrm{CM}_{1}$ and $\mathrm{CM}_{5}$ leads. Recordings were scanned using several different generations of AECG scanning equipment in routine use during the study. Ventricular rhythm evaluation included quanti- fication of the number of VT events ( $\geq 3$ consecutive ventricular complexes; classified as nonsustained if the total run was $<30 \mathrm{~s}$ ) and number of ventricular contractions in the longest VT run on each AECG [15]. Recordings were also analyzed for atrial fibrillation (AF) and/or atrial flutter (Aflutter). AECG was performed 8.1 \pm 3.3 months (range 1.5-17.0) after MVS; a subgroup (51/57 patients, $89.5 \%$ ) also underwent AECG during a similar interval before operation (average $4.4 \pm 4.4$ months, range $0.0-17.3$ ), permitting secondary analyses.

\section{Radionuclide Cineangiography}

RNCA was performed with the patient in supine position at rest using an ECG-gated equilibrium method analogous to that previously described $[16,17]$. In these studies, red cells were labeled in vivo with stannous pyrophosphate infused intravenously prior to administration of $15-25 \mathrm{mCi}$ of ${ }^{99} \mathrm{mTc}$. LVEF was computed by a method analogous to our previously reported count-based procedure, validated by comparison with contrast angiography $[17,18]$. During the course of this study, the predominant mode of LVEF analysis changed from use of a single region of interest (ROI) at end-diastole to separate end-systolic and end-diastolic ROI; absolute values of LVEF differ depending on which procedure is used: 2 ROI values generally are 5-15\% higher than 1 ROI value. Since we altered our procedure during the course of the study but already had recorded values using the original 1 ROI method, our analysis of LVEF is based on adjusted values, calculated using a random subgroup of 30 preoperative studies and a different random subgroup of 30 postoperative studies; each group was analyzed both by 1 and 2 ROI to determine the difference in values between the methods. Adjustment for values obtained with 1 ROI was determined from the paired difference between measured LVEF of 1 and 2 ROI rather than from absolute values; thus, $11 \%$ ('ejection fraction units') were added to preoperative single ROI values, and $16 \%$ were added to postoperative single ROI values. Currently, resting $\mathrm{LVEF}<10 \%$ above the lower limit of normal is considered an indication for MVS [19] and is used as a 'high risk descriptor' indicating need for MVS in this study. Subnormal RVEF was calculated and defined as $<35 \%$, as in our previous publications $[7,8]$. All but 1 patient underwent both pre- $(\mathrm{n}=57)$ and postoperative $(\mathrm{n}=56)$ RNCA; these were performed within average $0.8 \pm 2.5$ months (range $0.0-14.4$ ) of preoperative AECG and within average $0.5 \pm 1.8$ months (range $0.0-11.9$ ) of postoperative AECG.

\section{Follow-Up and Definition of Endpoints}

Patients were followed through November 2011 by physical examination or by telephone call or postal questionnaire to the patient, relative or physician to determine the vital status and occurrence of intercurrent events. Cause of death among decedents was determined by review of medical and vital records, supplemented by information furnished by the patients' health care provider and/ or surviving family members or significant others. Average followup was $9.52 \pm 3.49$ years (range 1.98-15.5) among endpoint-free patients; $24 / 27$ (89\%) of these patients were followed for at least 5 years postoperatively. SD was defined as either witnessed unexpected arrest (resuscitated or nonresuscitated) in a patient who was previously stable or an unwitnessed unexpected death in a patient seen and apparently stable within the previous $24 \mathrm{~h}$; CD was defined as death resulting from heart failure (HF), determined by the primary physician and cardiologist, in addition to all SD (myocardial infarction was also a potential endpoint, but none occurred). 
Statistical Analysis

Summary data are expressed as the mean \pm standard deviation or as number and percentage, as appropriate. McNemars symmetry $\chi^{2}$ test was used to compare the preoperative versus postoperative presence of VT, AF or Aflutter and subnormal resting LVEF and RVEF. Pre- to postoperative differences in resting LVEF and RVEF, number of episodes of VT and maximum number of premature ventricular contractions on AECG, each evaluated as interval data, were analyzed by paired t test or the Wilcoxon rank sum test, as appropriate.

Kaplan-Meier product limit estimate curves were constructed and compared by log-rank testing to determine the relation of arrhythmia presence or systolic performance descriptors (defined postoperatively for primary analysis and preoperatively for secondary analysis) with outcomes, unadjusted for other variables. For these analyses, the distributions of the number of VT events on each AECG were analyzed in two different ways: (1) 0 versus 1 versus $>1 \mathrm{VT}$ events, and (2) with 0 and $1 \mathrm{VT}$ events aggregated versus $>1$ VT events; resting RVEF was analyzed as subnormal $(<35 \%)$ versus normal $(\geq 35 \%)$, and resting LVEF was analyzed as subnormal $(<55 \%)$ versus normal $(\geq 55 \%)$. RVEF and LVEF were also analyzed as continuous variables by univariable Cox regression methodology. For the primary analysis, follow-up began on the date of the postoperative AECG or RNCA, as appropriate; for secondary analyses, follow-up began at the time of the last preoperative objective evaluation. Patients were censored from further analysis if they underwent cardiovascular reoperation $(n=11)$ or defibrillator implantation (1 patient). Patients who died due to prosthetic valve failure $(n=1)$ or of clearly noncardiac causes $(n=$ 5 ) were also censored at the time of occurrence.

Forward stepwise multivariable Cox regression analysis (entry and removal thresholds: 0.05 and 0.10 , respectively) was performed pair-wise (two variables in one model), with and without interaction terms, to define the independent or additive prognostic value of any VT or functional descriptor that predicted CD in univariable analysis. (Multivariable analysis was not undertaken for SD due to the limited number of events.) Variables entered into these models were partitioned according to the same segregation points used for univariable analysis. A series of Cox model analyses was also used to adjust for potential confounding by age, gender, etiology (mitral valve prolapse vs. other etiologies), chronic use of antiarrhythmics, valve repair versus replacement, or preoperative New York Heart Association functional class (NYHA FC). Analyses used SPSS version 15.0 (Chicago, Ill., USA). p values $\leq 0.05$ were considered statistically significant; $p$ values $>0.05$ but $<0.1$ were considered statistical trends.

\section{Results}

\section{Cohort Characteristics}

Of the 57 analyzed patients, most were middle-aged females, 35 (61\%) underwent valve replacement and 22 (39\%) had valve repair. Hemodynamically important nonischemic MR was secondary to mitral valve prolapse in three fourths of the patients, and rheumatic heart disease, idiopathic ruptured chordae and endocarditis in
Table 1. Baseline characteristics of the cohort

\begin{tabular}{lc}
\hline Variable & $\mathrm{n}$ \\
\hline Average age at surgery, years & $58 \pm 12[29-77]$ \\
Gender, male & $27(47)$ \\
Etiology of MR & \\
$\quad$ Mitral valve prolapse & $43(75)$ \\
$\quad$ Rheumatic heart disease & $11(19)$ \\
$\quad$ Idiopathic ruptured chordae & $8(14)$ \\
Endocarditis & $1(2)$ \\
NYHA functional class (preoperative) & \\
I & $22(39)$ \\
II & $13(23)$ \\
III & $19(33)$ \\
IV & $3(5)$ \\
Type of valve surgery & \\
Repair & $22(39)$ \\
Replacement & $35(61)$ \\
Type of prosthetic valve & \\
Mechanical & $23(66)$ \\
Bioprosthetic & $12(34)$ \\
Average cross-clamp time, min & $75 \pm 22[16-127]$ \\
Average pump time, min & $103 \pm 34[48-244]$ \\
Antiarrythmics (preoperative) & $7(12)$ \\
Antiarrythmics (postoperative) & $10(18)$ \\
\hline
\end{tabular}

Figures in parentheses are percentages; figures in brackets are ranges.

others (some had combined etiologies). Prior to surgery, $39 \%$ were asymptomatic (NYHA FC I); of the remaining (symptomatic) patients, most were in NYHAFC III or II (table 1$)$. Ten patients $(18 \%)$ received long-term antiarrhythmic drugs (digoxin, amiodarone, procainamide, lidocaine, disopyramide, propafenone and/or quinidine).

\section{$V T$ and EF before and after MVS (table 2)}

VT occurred in one third of evaluable patients before MVS and in slightly more after MVS. Preoperative VT persisted after MVS in approximately half of those affected; a similar number had VT de novo after MVS. Repeated $(>1)$ VT episodes occurred in slightly more than half of those with any VT before and in a similar proportion after the operation. Among those with VT $>1$ episode before the operation, VT persisted postoperatively in 3 patients (30\%). AF/Aflutter was present in less than half of patients before and after MVS. LVEF and RVEF each were subnormal in approximately one quarter of patients before MVS; within 1 year after MVS, LVEF became subnormal in slightly more than half of the patients, though in most patients, RVEF returned to normal. 


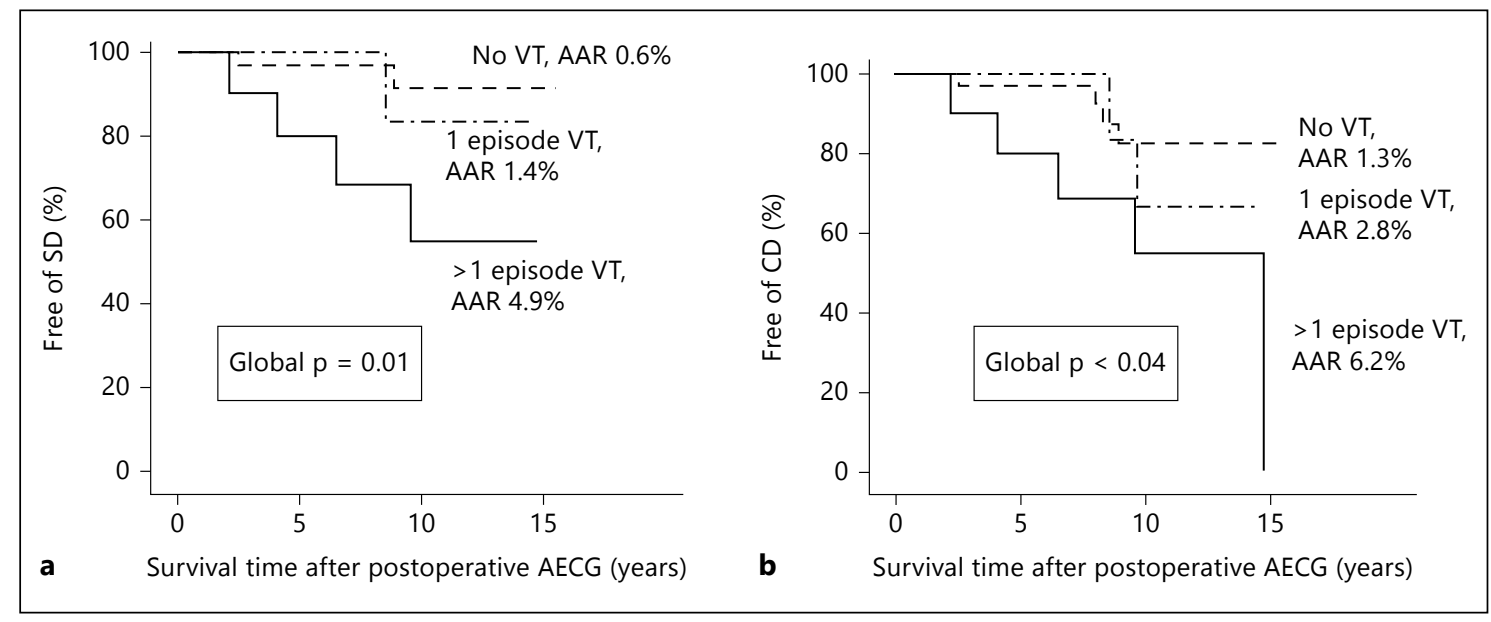

Fig. 1. Impact of postoperative nonsustained VT on postoperative CD. a VT ( 0 vs. 1 episode vs. $>1$ episode) versus survival free of $\mathrm{SD}$. For the analysis of VT $>1$ episode versus $\leq 1$ episode, $\mathrm{p}<0.01$; for no VT versus any VT, $\mathrm{p}=0.05$. b VT ( 0 vs. 1 episode vs. $>1$ episode) versus survival free of CD. For VT $>1$ episode versus $\leq 1$ episode, $\mathrm{p}=0.04$; for no VT versus any VT, $\mathrm{p}=0.07$.

Table 2. Arrhythmias and EFs before and after MVS

\begin{tabular}{|c|c|c|c|}
\hline Variable & Preoperatively & Postoperatively & $\mathrm{p}$ \\
\hline Nonsustained VT presence & $17(33.3)^{1}$ & $19(37.3)^{1,5}$ & NS \\
\hline Median nonsustained VT events & $0[0-97,2]^{1}$ & $0[0-41,2]^{1}$ & NS \\
\hline $\mathrm{AF} /$ Aflutter presence & $21(41.2)^{1,3}$ & $20(39.2)^{1,4}$ & NS \\
\hline Subnormal LVEF at rest & $15(26.8)^{2}$ & $30(53.6)^{2}$ & 0.001 \\
\hline Subnormal RVEF & $12(21.4)^{2}$ & $4(7.1)^{2}$ & 0.02 \\
\hline
\end{tabular}

Figures in parentheses are percentages; figures in brackets are ranges and the lower bound of the upper quintile. NS $=$ Not significant.

${ }^{1}$ Based on 51 evaluable cases. ${ }^{2}$ Based on 56 evaluable cases. ${ }^{3}$ AF $(n=20)$, Aflutter $(n=1) .{ }^{4}$ AF $(n=20)$, Aflutter $(n=0) .{ }^{5}$ Persistent nonsustained VT $(n=9)$, new postoperative nonsustained VT $(n=10)$.

\section{Events during Follow-Up}

From postoperative AECG to end of data acquisition, 16 patients died [ 7 suddenly, 4 due to HF, 5 due to noncardiac causes (stroke, prostate cancer, esophageal cancer, kidney failure and sepsis, 1 patient each)]. In our prospectively studied cohort, 1 death (from stroke) occurred before the initial AECG in a patient who did not qualify for this analysis.

\section{Prediction of CD from Postoperative VT and EF}

Of 19 patients with persistent or new VT after MVS, 7 died (5 suddenly, 1 due to HF, 1 noncardiac). Five deaths (4 SD, $1 \mathrm{HF}$ ) occurred among the 10 patients with $>1 \mathrm{VT}$ event after MVS. All episodes of VT were monomorphic with the majority of patients (55\%) having right bundle branch block-like QRS appearance in the $\mathrm{V}_{1}$ Holter vector. All episodes were nonsustained and lasted an average of $2.9 \pm 2.2 \mathrm{~s}$ and manifested an average cycle length of $448 \pm 86 \mathrm{~ms}$. For patients with $>1$ VT after MVS, the average annual risks (AARs) of SD and CD were 4.9 and $6.2 \%$, respectively. Repeated $(>1)$ VT episodes significantly predicted SD $(\mathrm{p}=0.01)$ and $\mathrm{CD}(\mathrm{p}<0.04)$ by univariable analysis (fig. 1). Any VT marginally predicted SD ( $\mathrm{p}=$ $0.05)$ but only trended toward predicting $C D(p=0.07)$. Neither the number of beats in the longest VT run nor the duration of that run (in seconds) predicted SD or CD. 


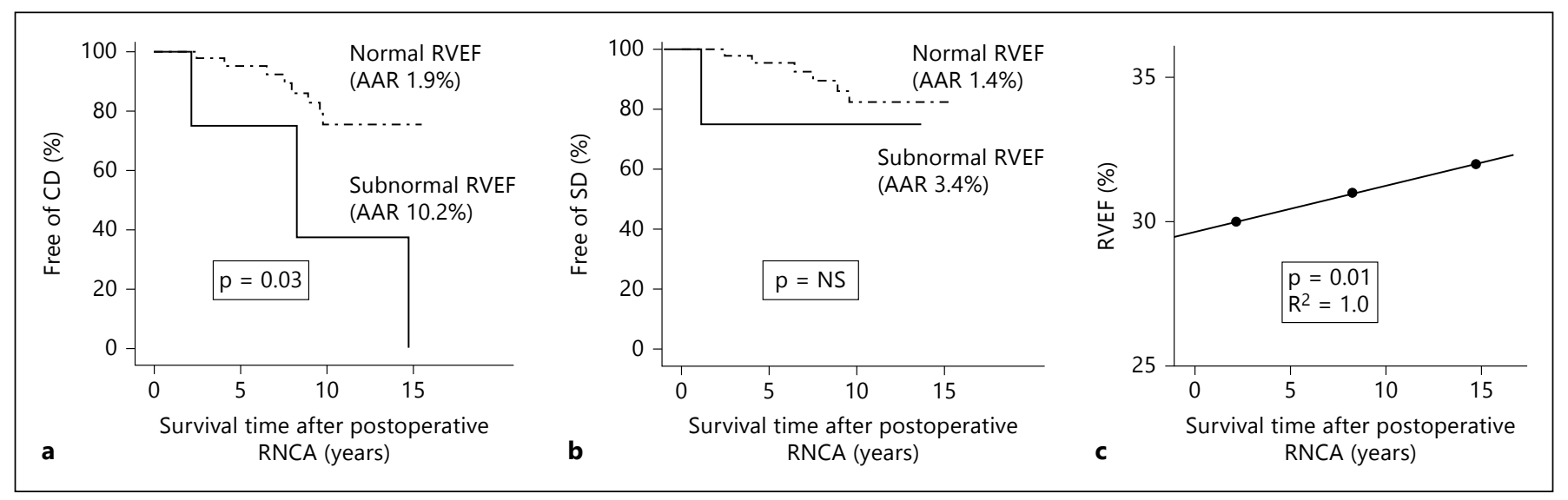

Fig. 2. Impact of subnormal RVEF on postoperative CD. Outcomes are SD and CD (SD or HF deaths). a RVEF stratified as subnormal or normal versus freedom from CD. b RVEF versus freedom from SD. c Severity of RVEF depression versus rate of progression to CD among the 3 of 4 patients with subnormal RVEF who died of cardiac causes.

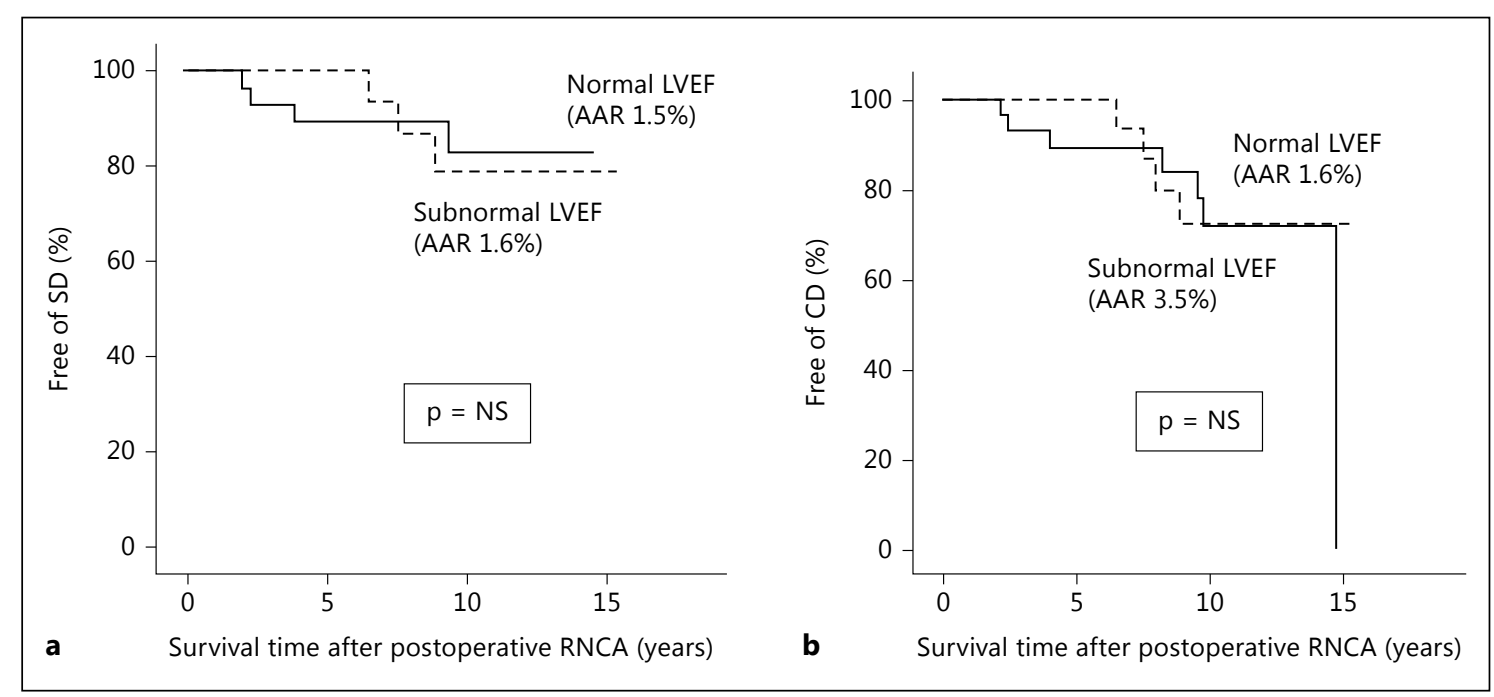

Fig. 3. Impact of subnormal LVEF on postoperative CD. Outcomes are SD and CD (SD or HF deaths). a LVEF stratified as subnormal or normal versus freedom from SD. b LVEF versus freedom from CD.

After MVS, all 4 patients with subnormal RVEF died (1 SD, $2 \mathrm{HF}, 1$ noncardiac). Among this group, AARs of $\mathrm{SD}$ and $\mathrm{CD}$ were 3.4 and $10.2 \%$, respectively. Subnormal RVEF predicted CD ( $p=0.03$; fig. $2 a)$ but not SD ( $p=$ not significant; fig. 2b). Absolute magnitude of RVEF was directly correlated with postoperative survival $(\mathrm{p}=$ 0.01 ; fig. $2 \mathrm{c})$. VT $>1$ episode also predicted CD $(\mathrm{p}=0.03)$ among those with subnormal RVEF but not among those with normal RVEF ( $p=$ not significant). VT $>1$ episode significantly predicted SD among patients with normal
RVEF ( $p=0.03$ ). When analysis was adjusted for variations in age, gender, MR etiology, or preoperative use of antiarrhythmics, both postoperative VT and RVEF predicted CD ( $\mathrm{p} \leq 0.05$, all adjustments). However, when postoperative VT and RVEF were considered in the same multivariable model, $\mathrm{CD}$ was predicted only by subnormal RVEF $(\mathrm{p}<0.04)$, indicating its greater value versus VT for prediction of this outcome. The independent predictive value of VT $>1$ episode and subnormal RVEF could not be evaluated for SD due to limited events. 
Among patients with subnormal LVEF after MVS, $10 / 30(33.3 \%)$ patients died (6 SD, $1 \mathrm{HF}, 3$ noncardiac). LVEF did not predict SD or CD either in univariable (fig. 3) or multivariable analyses. Nonsustained VT $>1$ episode predicted SD among those with subnormal LVEF $(\mathrm{p}=0.04)$ but not among those with normal LVEF ( $\mathrm{p}=$ not significant); VT $>1$ episode did not predict CD in either the subnormal or normal LVEF subgroups ( $p=$ not significant).

\section{Prediction of CD from Preoperative VT and EF}

When defined preoperatively, presence of VT, repeated $(>1)$ VT episodes, AF or Aflutter, LVEF and RVEF did not significantly predict postoperative SD or CD. Among those 3 patients with a VT $>1$ episode before and after MVS, 1 died suddenly. However, the independent predictive value of persistent VT $>1$ episode could not be evaluated due to the limited events.

\section{Discussion}

Our data indicate that when $>1$ episode of nonsustained VT is observed in a single AECG within 18 months after MVS for nonischemic MR, late postoperative cardiac mortality (especially due to SD) is significantly increased compared with absence of the arrhythmia. This is consistent with recent observations among patients with HF in the Sudden Cardiac Death in Heart Failure Trial in which $>2$ episodes of nonsustained VT, but not the presence of VT at baseline 24-hour AECG, predicted all-cause death [20]. Though subnormal RVEF after operation was a strong predictor of CD but not SD, among patients with normal RVEF, VT $>1$ episode predicted SD.

VT on AECG after MVS has not been reported previously to predict $\mathrm{CD}$. However, the relatively frequent occurrence of VT in unoperated MR $[8,21]$, and the importance of VT and other complex ventricular arrhythmias in predicting $\mathrm{SD}$ in unoperated $\mathrm{MR}$, described by several authors $[5,7,8,22,23]$, suggest that the myocardial effects of MR may predispose to VT, which often progresses to death. Although LV dysfunction is an important predisposing factor for fatal outcome in patients with other diseases who manifest VT [24-27], the present data suggest that the predisposition to arrhythmia persists even after the abnormal mechanical effects of MR have been relieved.

Apparent dissociation between RVEF and LVEF for late outcome after surgery are consistent with our earlier

Mitral Valve Surgery and Late Cardiac Death findings that the magnitude of preoperative RV (but not LV) dysfunction predicts late postoperative death in patients who undergo MVS when LV and RV dysfunction are established before MVS [4] and among patients who undergo surgery for concomitant MR and aortic regurgitation [14]. This suggestion is supported by our finding that subnormal RVEF after surgery is also predictive and may add to the impact of VT. However, in our study, $>1$ VT episode predicted SD even in patients with normal RVEF, suggesting that the myocardial predisposition to ventricular arrhythmia is not exclusively related to RV dysfunction. Although the reason for this finding is not completely understood, it may relate to an increased incidence of bundle-branch reentry VT that is observed after valve surgery [28]. This type of sustained VT has been seen predominantly in the first postoperative month in retrospective studies of patients undergoing electrophysiologic evaluation after valve surgery for suspected or documented arrhythmia $[28,29]$. In contrast to these retrospective studies, we prospectively followed all patients undergoing surgery for nonischemic MR, but did not perform an electrophysiologic study to define VT types. Scar-related VT has also been associated with valve surgery, predominantly in patients with comorbid coronary heart disease (and subnormal LV function) [28, 29]. Such patients were excluded from our study.

The importance of identifying patients at risk for late postoperative $\mathrm{CD}$ is suggested by the studies of Hammermeister et al. [6], who found that $81 \pm 4$ and $79 \pm 4 \%$ of patients who had undergone mechanical and bioprosthetic mitral valve replacement, respectively, died within 15 years after surgery; among these, 31 and 26\% were SD. The current tendency to perform mitral valve repair rather than replacement for most patients with $M R$, and to perform surgery relatively earlier than in past years, has resulted in better short- and longer-term outcomes [3033]. However, successful surgery often did not prevent preoperative VT persistence in our patients, even if LVEF was well preserved. Given the prognostic value of postoperative VT $>1$ episode, this finding suggests that MVS alone may be insufficient to optimally protect patients with MR, even when LVEF is preserved. Additional preventive strategies, perhaps including implantation of internal cardiac defibrillators among those at risk, may need to be considered. Our data further suggest that, in seeking patients who are at relatively high risk after the operation, rhythm analysis should be supported by RVEF determination.

Although our findings suggest that routine assessment of ventricular rhythm is important for risk stratification 
after MVS, this study does not define the optimal evaluation regimen, either in terms of timing or assessment frequency. We sampled cardiac rhythm by AECG relatively infrequently. However, as a proof of principle, the magnitude of AAR for SD (4.9\%) and CD (6.2\%) among those with $>1$ VT episode on a single AECG suggests that this measure is useful. Perhaps assessment earlier than a maximum of 18 months after surgery would be more effective if remedial action is to be undertaken. Nonetheless, since only 1 death occurred in our series (from stroke) before the initial AECG, and only 1 occurred in our patients who did not qualify for this analysis, the possibility of earlier death may not negate the value of VT assessment even as late as 18 months after surgery.

We did not demonstrate a relation of postoperative LVEF with outcome. This association was expected in view of earlier findings [34] specifically relating preoperative LVEF to postoperative survival $[3,35,36]$. Inferences drawn from our data are limited by the relatively small size of our population and the relatively small range of postoperative LVEF, minimizing the likelihood of finding a relation even if it truly exists. In addition, the long recruitment interval and relatively long follow-up inevitably imply that changes in surgical techniques might have resulted in variation in our results. This is a universal problem with long-term studies but our data nonetheless suggest an important principle that has not previously been assessed.
In summary, our data suggest the importance of rhythm and RVEF determination after surgery for MR. Additional studies will be needed to optimally define the regimen for such assessment and the remedial strategies that should be developed as a result.

\section{Acknowledgement}

During the performance of a portion of this work, Dr. Borer was supported in part as The Gladys and Roland Harriman Professor of Cardiovascular Medicine, Dr. Krieger as The Michel Bergerac Professor of Cardiothoracic Surgery and Dr. Isom as The Terry Allen Kramer Professor of Cardiothoracic Surgery, Weill Cornell Medical College. In addition, this work was supported by grants from the National Heart Lung and Blood Institute, Bethesda, Md. (RO1-HL-26504, J.S. Borer), The Howard Gilman Foundation, New York, N.Y., The Schiavone Family Foundation, White House Station, N.J., The Charles and Jean Brunie Foundation, Bronxville, N.Y., The David Margolis Foundation, New York, N.Y., The American Cardiovascular Research Foundation, New York, N.Y., The Irving A. Hansen Foundation, New York, N.Y., The Mary A.H. Rumsey Foundation, New York, N.Y., The Messinger Family Foundation, New York, N.Y., The Daniel and Elaine Sargent Charitable Trust, New York, N.Y., and by much appreciated gifts from Donna and William Acquavella, New York, N.Y., Maryjane Voute Arrigoni and the late William Voute, Bronxville, N.Y., Gerald Tanenbaum, New York, N.Y., and Suzanne and the late Stephen Weiss, Greenwich, Conn., USA.

\section{References}

1 Chaffin JS, Daggett WM: Mitral valve replacement: a nine-year follow-up of risks and survivals. Ann Thorac Surg 1979;27:312-319.

2 Horstkotte D, Loogen F, Kleikamp G, Schulte HD, Trampisch HJ, Bircks W: Effect of prosthetic heart valve replacement on the natural course of isolated mitral and aortic as well as multivalvular diseases. Clinical results in 783 patients up to 8 years following implantation of the Björk-Shiley tilting disc prosthesis. $\mathrm{Z}$ Kardiol 1983;72:494-503.

-3 Enriquez-Sarano M, Tajik AJ, Schaff HV, Orszulak TA, Bailey KR, Frye RL: Echocardiographic prediction of survival after surgical correction of organic mitral regurgitation. Circulation 1994;90:830-837.

4 Wencker D, Borer JS, Hochreiter C, Devereux RB, Roman MJ, Kligfield P, Supino P, Krieger K, Isom OW: Preoperative predictors of late postoperative outcome among patients with nonischemic mitral regurgitation with "high risk' descriptors and comparison with unoperated patients. Cardiology 2000;93:37-42.
5 Delahaye JP, Gare JP, Viguier E, Delahaye F, De Gevigney G, Milon H: Natural history of severe mitral regurgitation. Eur Heart J 1991; 12(suppl B):5-9.

6 Hammermeister K, Sethi GK, Henderson WG, Grover FL, Oprian C, Rahimtoola SH: Outcomes 15 years after valve replacement with a mechanical versus a bioprosthetic valve: final report of the Veterans Affairs randomized trial. J Am Coll Cardiol 2000;36:1152-1158.

7 Hochreiter C, Niles N, Devereux RB, Kligfield P, Borer JS: Mitral regurgitation: relationship of noninvasive descriptors of right and left ventricular performance to clinical and hemodynamic findings and to prognosis in medically and surgically treated patients. Circulation 1986;73:900-912.

$>8$ Kligfield P, Hochreiter C, Niles N, Devereux $\mathrm{RB}$, Borer JS: Relation of sudden death in pure mitral regurgitation, with and without mitral valve prolapse, to repetitive ventricular arrhythmias and right and left ventricular ejection fractions. Am J Cardiol 1987;60:397-399.
Grigioni F, Enriquez-Sarano M, Ling LH, Bailey KR, Seward JB, Tajik AJ, Frye RL: Sudden death in mitral regurgitation due to flail leaflet. J Am Coll Cardiol 1999;34:20782085.

10 Meyer MA, von Segesser LK, Hurni M, Stumpe F, Eisa K, Ruchat P: Long-term outcome after mitral valve repair: a risk factor analysis. Eur J Cardiothorac Surg 2007;32: 301-307.

11 Enriquez-Sarano M, Schaff HV, Orszulak TA, Tajik AJ, Bailey KR, Frye RL: Valve repair improves the outcome of surgery for mitral regurgitation. A multivariate analysis. Circulation 1995;91:1022-1028.

-12 Rosen SE, Borer JS, Hochreiter C, Supino P, Roman MJ, Devereux RB, Kligfield P, Bucek $\mathrm{J}$ : Natural history of the asymptomatic/minimally symptomatic patient with severe mitral regurgitation secondary to mitral valve prolapse and normal right and left ventricular performance. Am J Cardiol 1994;74:374380 
13 Viguier E, Delahaye JP, de Gevigney G, Gare JP, Delahaye F, Michel PL, Thomas D, Leclercq F: Pre- and postoperative ventricular arrhythmia in mitral valve insufficiency. Arch Mal Coeur Vaiss 1994;87:439-444.

14 Niles N, Borer JS, Kamen M, Hochreiter C, Devereux RB, Kligfield P: Preoperative left and right ventricular performance in combined aortic and mitral regurgitation and comparison with isolated aortic or mitral regurgitation. Am J Cardiol 1990;65:1372-1378.

15 el-Sherif N, Denes P, Katz R, Capone R, Mitchell LB, Carlson M, Reynolds-Haertle R: Definition of the best prediction criteria of the time domain signal-averaged electrocardiogram for serious arrhythmic events in the postinfarction period. The Cardiac Arrhythmia Suppression Trial/Signal-Averaged Electrocardiogram (CAST/SAECG) Substudy Investigators. J Am Coll Cardiol 1995;25:908914.

16 Borer JS, Bacharach SL, Green MV, Kent KM, Epstein SE, Johnston GS: Real-time radionuclide cineangiography in the noninvasive evaluation of global and regional left ventricular function at rest and during exercise in patients with coronary-artery disease. N Engl J Med 1977; 296:839-844.

17 Borer JS, Kent KM, Bacharach SL, Green MV, Rosing DR, Seides SF, Epstein SE, Johnston GS: Sensitivity, specificity and predictive accuracy of radionuclide cineangiography during exercise in patients with coronary artery disease. Comparison with exercise electrocardiography. Circulation 1979;60:572-580.

18 Green MV, Brody WR, Douglas MA, Borer JS, Ostrow HG, Line BR, Bacharach SL, Johnston GS: Ejection fraction by count rate from gated images. J Nucl Med 1978;19:880-883.

19 Bonow RO, Carabello BA, Kanu C, de Leon AC Jr, Faxon DP, Freed MD, Gaasch WH, Lytle BW, Nishimura RA, O'Gara PT, O'Rourke RA, Otto CM, Shah PM, Shanewise JS, Smith SC Jr, Jacobs AK, Adams CD, Anderson JL, Antman EM, Fuster V, Halperin JL, Hiratzka LF, Hunt SA, Nishimura R, Page RL, Riegel B: ACC/ AHA 2006 guidelines for the management of patients with valvular heart disease: a report of the American College of Cardiology/American Heart Association Task Force on Practice Guidelines (writing committee to revise the 1998 Guidelines for the Management of Patients With Valvular Heart Disease): developed in collaboration with the Society of Cardiovascular Anesthesiologists: endorsed by the Society for Cardiovascular Angiography and Interventions and the Society of Thoracic Surgeons. Circulation 2006;114:e84-e231.
20 Moore HJ, Fletcher RD, Platt MD, Boineau R, Anderson J, Johnson G, Hellkamp A, Reinhall P, Poole JE, Mark DB, Lee KL, Bardy GH: SCD-HEFT: non-sustained ventricular tachycardia on baseline Holter monitor association with overall mortality. J Am Coll Cardiol 2011; 57:41.

21 Kligfield P, Hochreiter C, Kramer H, Devereux RB, Niles N, Kramer-Fox R, Borer JS: Complex arrhythmias in mitral regurgitation with and without mitral valve prolapse: contrast to arrhythmias in mitral valve prolapse without mitral regurgitation. Am J Cardiol 1985;55:1545-1549.

22 Duren DR, Becker AE, Dunning AJ: Longterm follow-up of idiopathic mitral valve prolapse in 300 patients: a prospective study. J Am Coll Cardiol 1988;11:42-47.

23 Boudoulas H, Schaal SF, Stang JM, Fontana ME, Kolibash AJ, Wooley CF: Mitral valve prolapse: cardiac arrest with long-term survival. Int J Cardiol 1990;26:37-44.

24 Bigger JT Jr, Fleiss JL, Kleiger R, Miller JP, Rolnitzky LM: The relationships among ventricular arrhythmias, left ventricular dysfunction, and mortality in the 2 years after myocardial infarction. Circulation 1984;69:250258.

25 Schulze RA Jr, Strauss HW, Pitt B: Sudden death in the year following myocardial infarction. Relation to ventricular premature contractions in the late hospitals phase and left ventricular ejection fraction. Am J Med 1977; 62:192-199.

26 Rouleau J, Shenasa M, de Champlain J, Nadeau R: Predictors of survival and sudden death in patients with stable severe congestive heart failure due to ischemic and nonischemic causes: a prospective long term study of 200 patients. Can J Cardiol 1990;6:453-460.
27 Szabo BM, van Veldhuisen DJ, Crijns HJ, Wiesfeld AC, Hillege HL, Lie KI: Value of ambulatory electrocardiographic monitoring to identify increased risk of sudden death in patients with left ventricular dysfunction and heart failure. Eur Heart J 1994;15:928-933.

28 Narasimhan C, Jazayeri MR, Sra J, Dhala A, Deshpande S, Biehl M, Akhtar M, Blanck Z: Ventricular tachycardia in valvular heart disease: facilitation of sustained bundle-branch reentry by valve surgery. Circulation 1997;96: 4307-4313.

29 Eckart RE, Hruczkowski TW, Tedrow UB, Koplan BA, Epstein LM, Stevenson WG: Sustained ventricular tachycardia associated with corrective valve surgery. Circulation 2007; 116:2005-2011.

30 Lee EM, Shapiro LM, Wells FC: Superiority of mitral valve repair in surgery for degenerative mitral regurgitation. Eur Heart J 1997; 18: 655-663.

- 31 Perier P, Deloche A, Chauvaud S, Fabiani JN, Rossant P, Bessou JP, Relland J, Bourezak H, Gomez F, Blondeau P, et al: Comparative evaluation of mitral valve repair and replacement with Starr, Björk, and porcine valve prostheses. Circulation 1984;70:I187-I192.

- 32 Sousa Uva M, Dreyfus G, Rescigno G, al Aile N, Mascagni R, La Marra M, Pouillart F, Pargaonkar S, Palsky E, Raffoul R, Scorsin M, Noera G, Lessana A: Surgical treatment of asymptomatic and mildly symptomatic mitral regurgitation. J Thorac Cardiovasc Surg 1996; 112:1240-1248, discussion 1248-1249.

-33 Tribouilloy CM, Enriquez-Sarano M, Schaff HV, Orszulak TA, Bailey KR, Tajik AJ, Frye RL: Impact of preoperative symptoms on survival after surgical correction of organic mitral regurgitation: rationale for optimizing surgical indications. Circulation 1999;99:400405.

-34 Enriquez-Sarano M, Schaff HV, Orszulak TA, Bailey KR, Tajik AJ, Frye RL: Congestive heart failure after surgical correction of mitral regurgitation. A long-term study. Circulation 1995;92:2496-2503.

35 Zile MR, Gaasch WH, Carroll JD, Levine HJ: Chronic mitral regurgitation: predictive value of preoperative echocardiographic indexes of left ventricular function and wall stress. J Am Coll Cardiol 1984;3:235-242.

- 36 Phillips HR, Levine FH, Carter JE, Boucher CA, Osbakken MD, Okada RD, Akins CW, Daggett WM, Buckley MJ, Pohost GM: Mitral valve replacement for isolated mitral regurgitation: analysis of clinical course and late postoperative left ventricular ejection fraction. Am J Cardiol 1981;48:647-654. 